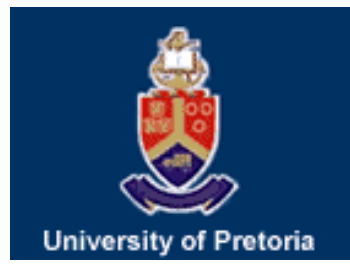

University of Pretoria

Department of Economics Working Paper Series

\author{
Is the Permanent Income Hypothesis Really Well-Suited for \\ Forecasting? \\ Rangan Gupta \\ University of Pretoria \\ Emmanuel Ziramba \\ University of South Africa \\ Working Paper: 2009-09 \\ March 2009
}

Department of Economics

University of Pretoria

0002, Pretoria

South Africa

Tel: +27 124202413

Fax: +27 123625207 


\title{
Is the Permanent Income Hypothesis Really Well-Suited for Forecasting?
}

\author{
Rangan Gupta* and Emmanuel Ziramba ${ }^{\#}$
}

\begin{abstract}
This paper first tests the restrictions implied by Hall's (1978) version of the permanent income hypothesis $(\mathrm{PIH})$ obtained from a bivariate system of labor income and savings, using quarterly data over the period of 1947:01 to 2008:03 for the US economy, and then uses the model to forecast changes in labor income over the period of 1991:01 to 2008:03. First, our results indicate the overwhelming rejection of the restrictions on the data implied by the PIH. Second, we found that, when compared to univariate and bivariate versions of classical and Bayesian Vector Autoregressive (VAR) models, the PIH model, in general, is outperformed by all other models in terms of the average RMSEs for one- to eight-quarters-ahead forecasts for the changes in labor income. Finally, as far as forecasting is concerned, we found the most tight Gibbs sampled univarite Bayesian VAR to perform the best. In sum, we do not find evidence for the US data to be consistent with the PIH, neither does the PIH model perform better relative to alternative atheoretical models in forecasting changes in labor income over an out of sample horizon that was characterized by high degree of volatility for the variable of interest.
\end{abstract}

JEL Classifications: E17, E21, E27, E37, E47.

Keywords: Permanent Income Hypothesis; Forecast accuracy; Gibbs Sampling

\section{Introduction}

This paper first tests the restrictions implied by Hall's (1978) version of the permanent income hypothesis (PIH) obtained from a bivariate system of labor income and savings, using quarterly data over the period of 1947:01 to 2008:03 for the US economy, and then uses the model to forecast changes in labor income over the period of 1991:01 to 2008:03. The forecast performance of the PIH model is compared using the Root Mean Squared Error for one to eight-quarters-ahead forecasts generated from the univariate and bivariate versions of both classical and Bayesian variants of the Vector Autoregressive (VAR) model. In addition to this, given that the period of 1991:01 to 2008:03 was characterized by high levels of variation in the changes in labor income, as indicated in Figure 1, we also use a Gibbs-sampled version of the Bayesian VAR (BVAR) model characterized by heteroscedastic disturbances to capture the nonconstant variance in the data over the out-of-sample horizon.

\section{[INSERT FIGURE 1]}

\footnotetext{
* To whom correspondence should be addressed. Associate Professor, Department of Economics, University of Pretoria, Pretoria, 0002, South Africa, Email: Rangan.Gupta@up.ac.za. Phone: +27 12420 3460, Fax: +27 123625207.

\# Senior Lecturer, Department of Economics, University of South Africa, P.O. Box 392, Pretoria, 0003, South Africa, Email: zirame@unisa.ac.za, Phone: +27 124294486.
} 
The motivation of our study emanates from the work of Ireland (1995). In this paper, the author first tested for the restrictions implied by Hall's (1978) version of PIH, as derived by Campbell (1987), over the period of 1959:01 to 1994:03 and then used the PIH model to forecast changes in labor income over the period of 1971:01 to 1994:03. Ireland (1995) failed to accept the restrictions, but indicated that the PIH must be judged on its ability to forecast better than alternative econometric models. In this backdrop, the objective of this paper is simply to revisit the forecasting ability of the PIH model, relative to standard alternative econometric models, over an out-of-sample horizon characterized by high degree of volatility in the variable of interest, namely, the changes in the aggregate labor income, based on longer data set. To the best of our knowledge, this is the first attempt to compare the ability of a PIH model in forecasting change in labor income, relative to alternative Bayesian models, and in particular, Gibbs sampled BVARs that accounts for non-constant variance in the variable of interest. ${ }^{1}$

The permanent income hypothesis has its origins in Irving Fisher's (1907) theory of interest rate. In the next section, we start of by reviewing Fischer's analysis, followed by Hall's (1978) version of the permanent income hypothesis. Section 3 presents the empirical estimates and the test for the restrictions implied by the PIH model, following the works of Campbell (1987) and Ireland (1995). Section 4 outlines the basics of the alternative models used for the forecasting exercise, while Section 5 presents the forecasting results. Finally, Section 6 concludes.

\section{Tracing the History of PIH}

\subsection{Fisher's Theory of interest and the PIH}

Fisher (1907) considers an inter-temporal household utility maximization over two periods. The representative household receives income in both periods makes its consumption and savings decisions. The household's preferences at the two time periods are represented by the indifference curves. The household seeks to maximize utility subject to a budget constraint.

The inter-temporal price is represented by the fixed interest rate (r) which the household faces. The slope of each indifference curve is determined by the household's marginal rate of intertemporal substitution or the rate at which it is willing to exchange goods at time 1 for goods at time 0 .

In order to maximize utility the household equates the its marginal rate of inter-temporal substitution to the slope of the budget line $(1+r)$. The point of tangency gives the consumption pair $\left(\mathrm{c}_{0}, \mathrm{c}_{1}\right)$ on indifference curve $\mathrm{U}_{0}$ as the optimal combination. The household's savings will be given by $\mathrm{s}_{0}=\mathrm{y}_{0}-\mathrm{c}_{0}$. All income points along a given budget constraint have the same present value, equal to

$$
P V=y_{0}+\frac{y_{1}}{(1+r)}
$$

One implication of Fisher's theory is that the household's consumption choice depends only on

\footnotetext{
${ }^{1}$ See Rao (2005) and Rao and Sharma (2007) for two recent studies on the application of Hall's (1978) version of PIH using data from Fiji, and Fiji and Australia respectively. Also refer to Dejuan et al. (2004) for a direct test of the PIH applied to the US economy.
} 
the present value of its income pair $\left(\mathrm{y}_{0}, \mathrm{y}_{1}\right)$, not on $\mathrm{y}_{0}$ and $\mathrm{y}_{1}$ separately. If second period income increases the present value of the household's income pair will increase. It shifts the consumer's budget line to the right. The household will also reduce its time 0 savings to $s_{0}{ }^{\prime}=y_{0^{-}} c_{0}{ }^{\prime}$. This confirms the second implication of Fisher's theory, that the household saves more when it expects future income to be high. This suggests that data on household savings may be used to forecast future income.

Friedman's (1957) permanent income hypothesis generalizes Fisher's analysis to a model in which there are more than two periods and the consumer faces uncertainty about its future income prospects. In this setup the present value becomes

$$
P V=\sum_{t=0}^{\infty} \frac{E y_{t}}{(1+r)^{t}} \text {, }
$$

where $y_{t}$ represents the household's expected income at time $t$.

Friedman defines the household's permanent income $\mathrm{y}^{\mathrm{p}}$ as the constant income level that, if received with certainty in each period $t$, has the same present value as the household's actual income path. That is, $\mathrm{y}^{\mathrm{p}}$ satisfies

$$
\sum_{t=0}^{\infty} \frac{y^{p}}{(1+r)^{t}}=P V=\sum_{t=0}^{\infty} \frac{E y_{t}}{(1+r)^{t}} .
$$

Equation (3) simplifies to

$$
y^{p}=\frac{r}{1+r} P V
$$

Friedman expresses the household's date 0 consumption as a function of permanent and also says that the household borrows to increase consumption today when it expects higher income in the future. Thus, it saves less when it expects higher future income.

\subsection{Hall's version of the PIH}

Hall (1978) develops a mathematical version of the permanent income hypothesis that indicates how data on savings can be used to forecast changes in income. He assumes an infinitely- lived representative household whose future income is uncertain and has expected utility given by

$$
E \sum_{t=0}^{\infty} \beta^{t} u\left(c_{t}\right)
$$

where $\mathrm{E}$ once again represents the household's expectation, $\mathrm{u}\left(\mathrm{c}_{t}\right)$ measures its utility from consuming amount $c_{t}$ at time $t$, and $\beta$ is the discount factor whose value lies between zero and one.

The representative household starts period $t$ with assets of value $A_{t}$. It receives interest on these 
assets at rate $\mathrm{r}$ equal to $\mathrm{y}_{\mathrm{kt}}$. It also receives labor income $\mathrm{y}_{\mathrm{lt}}$ during period $\mathrm{t}$. At the end of period $\mathrm{t}$, the household divides its total income $\mathrm{y}_{\mathrm{t}}=\mathrm{y}_{\mathrm{kt}}+\mathrm{y}_{\mathrm{lt}}$ between consumption ct and saving $\mathrm{s}_{\mathrm{t}}=\mathrm{y}_{\mathrm{t}}-\mathrm{c}_{\mathrm{t}}$.

The household is able to borrow against future income labor income at the interest rate $\mathrm{r}$. Its borrowing is, however, constrained in the long run by the requirement that

$$
\lim _{t \rightarrow \infty} \frac{A_{t}}{(1+r)^{t}}=0
$$

Equation (6) can be used to derive equation (7).

$$
A_{t}=\sum_{j=0}^{\infty} \frac{c_{t+j}-y_{l t+j}}{(1+r)^{j+1}}
$$

(7)Equation (7) shows that

the household must repay any debt owed today $\left(-A_{t}\right)$ by setting future consumption $c_{t+j}$ below future labor income $\mathrm{y}_{\mathrm{lt}+j}$. This equation implies that $A_{t}=\sum_{j=0}^{\infty} \frac{E_{t} C_{t+j}}{(1+r)^{j+1}}-\sum_{j=0}^{\infty} \frac{E_{t} y_{l t+j}}{(1+r)^{j+1}}$,

Equation (8) states that the household's current level of assets $A_{t}$ must be adequate to cover any shortfall between the present value of expected future consumption and the present value of expected future labor income.

The utility maximization optimality condition is given by equation (9). This simply represents the tangency between the budget constraint and the household's indifference curve. It says that the household sets its expected marginal rate of inter-temporal substitution to its gross rate of interest $(1+r)$.

$$
u^{\prime}\left(c_{t}\right)=\beta(1+r) E_{t} u^{\prime}\left(c_{t+1}\right)
$$

The analysis assumes that the utility function is quadratic and separable in time and in equilibrium $r=\beta$. Given equation (1) and the assumptions above the Hall equation is given by:

$$
C_{t+1}=C_{t}+\varepsilon_{t}
$$

or

$$
\Delta C_{t}=\varepsilon_{t}
$$

where $\varepsilon$ is white noise. Hall (1978) argued that if expectations of life-time income are rational, the permanent income hypothesis implies that the change in consumption should be a random walk and his contribution has become known as the "Random Walk Hypothesis". Equation (10) implies that all the available information is used in period t to predict future consumption $C_{t+1}$. Equation (10) can also be represented as 
$c_{t}=E_{t} c_{t+1}$

Substituting equation (11) into equation (8) yields $C_{t}=r A_{t}+\frac{r}{1+r} \sum_{j=0}^{\infty} \frac{E_{t} y_{l t+j}}{(1+r)^{j}}$

The right-hand side of equation (12) represents the household's permanent income and this equation implies that consumption is determined by permanent income.

Using $\mathrm{y}_{\mathrm{kt}}=\mathrm{rA}_{\mathrm{t}}$ and $\mathrm{s}_{\mathrm{t}}=\mathrm{y}_{\mathrm{kt}}+\mathrm{y}_{\mathrm{lt}}-\mathrm{c}_{\mathrm{t}}$ and denoting the change in labor income by $\Delta \mathrm{y}_{\mathrm{lt}}=\mathrm{y}_{\mathrm{lt}}-\mathrm{y}_{\mathrm{lt}-1}$ we can rewrite equation (12) as

$S_{t}=-\sum_{j=1}^{\infty} \frac{E_{t} \Delta y_{l t+j}}{(1+r)^{j}}$

Equation (13) shows that the household's current savings $s_{t}$ equals the present value of the expected future decline in its labor income. Thus, the household saves more when it expects future decline in income, that is, negative values for $\Delta \mathrm{y}_{\mathrm{lt}+\mathrm{j}^{\circ}}$. This result is the second implication of the permanent income hypothesis and suggests that data on savings help to forecast future changes in labor income.

\section{Testing the PIH:}

Campbell (1987) showed exactly how Hall's version of the PIH can be used to formulate an econometric model for forecasting. Since the PIH implies that data on savings will help to forecast future changes in labor income, Campbell (1987) started with a bivariate vector autoregression (VAR) for change in labor income $\left(\Delta \mathrm{y}_{\mathrm{lt}}\right)$ and savings $\left(\mathrm{s}_{\mathrm{t}}\right)$ of the following form:

$$
\left[\begin{array}{l}
\Delta y_{k t} \\
s_{t}
\end{array}\right]=\left[\begin{array}{l}
\alpha(L) c(L) \\
c(L) d(L)
\end{array}\right]\left[\begin{array}{l}
\Delta y_{t-1} \\
s_{p-1}
\end{array}\right]+\left[\begin{array}{l}
u_{1 t} \\
u_{2 t}
\end{array}\right]
$$

where $a(L)=a_{1}+a_{2} L+a_{3} L^{2}+\ldots \ldots \ldots \ldots+a_{p} L^{p-1}, L$ is the lag operator, and $\mathrm{u}_{1 \mathrm{t}}$ and $\mathrm{u}_{2 \mathrm{t}}$ are serially uncorrelated errors. Campbell (1987) then showed that the relationship between savings and future labor income that was identified by Hall translates into a set of parameter restrictions which must hold on the VAR, and they take the following form²:

$a_{1}=c_{1}, \ldots, a_{p}=c_{p}, d_{1}-b_{1}=(1+r), b_{2}=d_{2}, \ldots \ldots, b_{p}=d_{p}$.

\footnotetext{
${ }^{2}$ Please refer to Appendix A of Ireland (1995) for further details.
} 
Using quarterly data, obtained from the Bureau of Economic Analysis (BEA), for the period 1947:1 to 2008:3, and following Ireland (1995) to generate the labor income and savings variable $^{3}$, we estimate the VAR as specified in equation (14), both with and without the PIH restrictions. The estimated models include three lags of each variable on the right-hand side. ${ }^{4}$

\section{[INSERT TABLE 1]}

In Table 1, panel (b) shows the equation of the labor income growth when permanent income constraints (15) are imposed on the VAR. Following Ireland (1995) the estimates assume $r=$ 0.01. Panel (a) shows the unconstrained equation for labor income growth. In both cases, the marginally negative sum of the coefficients on lagged savings indicates that a decrease in savings translates into a forecast of faster income growth, as implied by the permanent income hypothesis. An F-test rejects (in both cases) the null hypothesis that savings data do not help to forecast future income growth; the coefficients on the lags of savings are jointly significant at the 99 percent confidence level. Though, statistically significant, given that the sum of coefficients adds upto values of for the unconstrained and constrained models respectively, the role played by lagged savings in defining the process of labor income growth is economically insignificant.

Note that the coefficients of the constrained equation is quite similar to those of the unconstrained equation, providing mild evidence of the data being consistent with the permanent income hypothesis. However, a statistical test rejected the restrictions in equation (15) at the 95 percent confidence interval. ${ }^{5}$ Ireland (1995) argued that the permanent income hypothesis must be judged on its ability to forecast the data better than alternative models. Thus, the next section discusses the alternative models used in forecasting the changes in labor income, while the following section is devoted to the comparison of the PIH model with the other models in forecasting the change in the labor income.

\section{Alternative Models:}

The alternative models which were used for forecasting the changes in the labor income includes the univariate and bivariate version of the VAR, BVAR and the Gibbs sampled BVAR. In what follows, we present a brief outline of these models. ${ }^{6}$

VAR models, though atheoretical, are particularly useful for forecasting purposes. An unrestricted VAR model, as suggested by Sims (1980), can be written as follows:

$$
y_{t}=C+A(L) y_{t}+\varepsilon_{t}
$$

\footnotetext{
${ }^{3}$ Please refer to Appendix B of Ireland (1995) for further details on the data and the methodology followed to generate the two variables of our interest.

${ }_{4}^{4}$ The choice of 3 lags is based on the unanimity of the Akaike information criterion (AIC), the final prediction error (FPE) criterion and the Hannan-Quinn (HQ) information criterion applied to a stable VAR estimated with the two variables of concern. Note, stability, as usual, implies that no roots were found to lie outside the unit circle.

${ }^{5}$ King (1995) pointed out that formal hypothesis tests seldom fail to reject the implications of detailed mathematical models, and, hence, the rejection of the restrictions of Hall's (1978) model, should not be surprising.

${ }^{6}$ The discussion in this Section relies heavily on the discussion available in LeSage (1999) and Gupta and Sichei (2006), Gupta $(2006,2007)$.
} 
where $y$ is a $(n \times 1)$ vector of variables being forecasted; $A(L)$ is a $(n \times n)$ polynomial matrix in the backshift operator $L$ with lag length $p$, i.e., $A(L)=A_{1} L+A_{2} L^{2}+\ldots \ldots \ldots \ldots \ldots . . .+A_{p} L^{p} ; C$ is a $(n \times 1)$ vector of constant terms, and $\varepsilon$ is a $(n \times 1)$ vector of white-noise error terms. The VAR model uses equal lag length for all the variables of the model. One drawback of VAR models is that many parameters are needed to be estimated, some of which may be insignificant. This problem of overparameterization, resulting in multicollinearity and loss of degrees of freedom leads to inefficient estimates and large out-of-sample forecasting errors. One solution, often adapted, is simply to exclude the insignificant lags based on statistical tests. Another approach is to use near VAR, which specifies unequal number of lags for the different equations.

However, an alternative approach to overcome this overparameterization, as described in Littermann (1981), Doan et al (1984), Todd (1984), Littermann (1986), and Spencer (1993), is to use a BVAR model. The Bayesian method imposes restrictions on these coefficients by assuming that they are more likely to be near zero than the coefficients on shorter lags. However, if there are strong effects from less important variables, the data can override this assumption. The restrictions are imposed by specifying normal prior distributions with zero means and small standard deviations for all coefficients with the standard deviation decreasing as the lags increase. The exception to this is, however, the coefficient on the first own lag of a variable, which has a mean of unity. Litterman (1981) used a diffuse prior for the constant. This is popularly referred to as the 'Minnesota prior' due to its development at the University of Minnesota and the Federal Reserve Bank at Minneapolis.

Formally, as discussed above, the Minnesota prior means take the following form:

$$
\beta_{i} \sim N\left(0, \sigma_{\beta_{i}}^{2}\right) \text { and } \beta_{j} \sim N\left(0, \sigma_{\beta_{j}}^{2}\right)
$$

where $\beta_{i}$ denotes the coefficients associated with the lagged dependent variables in each equation of the VAR, while $\beta_{j}$ represents any other coefficient. In the belief that lagged dependent variables are important explanatory variables, the prior means corresponding to them are set to unity. However, for all the other coefficients, $\beta_{j}$ 's, in a particular equation of the $\mathrm{VAR}$, a prior mean of zero is assigned, to suggest that these variables are less important to the model.

The prior variances $\sigma_{\beta_{i}}^{2}$ and $\sigma_{\beta_{j}}^{2}$, specify uncertainty about the prior means $\bar{\beta}_{i}=1$, and $\bar{\beta}_{j}=0$, respectively. Because of the overparameterization of the VAR, Doan et al. (1984) suggested a formula to generate standard deviations as a function of small numbers of hyperparameters: $w, d$, and a weigting matrix $f(i, j)$. This approach allows the forecaster to specify individual prior variances for a large number of coefficients based on only a few hyperparameters. The specification of the standard deviation of the distribution of the prior imposed on variable $j$ in equation $i$ at lag $m$, for all $i, j$ and $m$, defined as $S(i, j, m)$, can be specified as follows:

$S(i, j, m)=[w \times g(m) \times f(i, j)] \frac{\hat{\sigma}_{i}}{\hat{\sigma}_{j}}$

with $f(i, j)=1$, if $i=j$ and $k_{i j}$ otherwise, with $\left(0 \leq k_{i j} \leq 1\right), g(m)=m^{-d}, d>0$. Note that $\hat{\sigma}_{i}$ is the estimated standard error of the univariate autoregression for variable $i$. The ratio $\hat{\sigma}_{i} / \hat{\sigma}_{j}$ scales the variables so as to account for differences in the units of measurement and, hence, causes 
specification of the prior without consideration of the magnitudes of the variables. The term $w$ indicates the overall tightness and is also the standard deviation on the first own lag, with the prior getting tighter as we reduce the value. The parameter $g(m)$ measures the tightness on lag $m$ with respect to lag 1 , and is assumed to have a harmonic shape with a decay factor of $d$, which tightens the prior on increasing lags. The parameter $f(i, j)$ represents the tightness of variable $j$ in equation $i$ relative to variable $i$, and by increasing the interaction, i.e., the value of $k_{i j}$, we can loosen the prior. ${ }^{7}$ Following Gupta (2007), we choose 0.1, 0.2 for the overall tightness $(w)$ and 1 and 2 for the harmonic lag decay parameter (d). Moreover, as in Dua and Ray (1995), we also report our results for a combination of $w=0.3$ and $d=0.5$. Finally, a symmetric interaction function, $f(i, j)$, is assumed with $k_{i j}=0.5$, as in LeSage (1999).

Traditionally, The Bayesian variants of the classical VARs are assumed to have an error structure that follows the Gauss-Markov assumptions and is estimated using Theil's (1971) mixed estimation technique, which involves supplementing the data with prior information on the distribution of the coefficients. In an artificial way, the number of observations and degrees of freedom are increased by one, for each restriction imposed on the parameter estimates. The loss of degrees of freedom due to over- parameterization associated with a VAR model is, therefore, not a concern in the BVAR model.

However, the estimation of the BVARs using Gibbs sampling allows us to incorporate outliers or non-constant variances. Note, with heteroscedastic errors, i.e., $\varepsilon \sim N\left(0, \sigma^{2} V\right), V=\operatorname{diag}\left(v_{1}, v_{2}, \ldots \ldots . ., v_{n}\right)$ with $V$ being a $n \times n$ matrix, with the relative variance terms $v_{1}, v_{2}, \ldots \ldots . ., v_{n}$ assumed to be fixed but unknown, we could have used generalised least squares to implement Theil's (1971) mixed estimation. But it is often the case that with the Gibbs sampling methodology, complex estimation problems, such as these, are simplified considerably by conditioning on unknown parameters, by assuming that these values are known. ${ }^{8}$ Moreover, as Kadiyala and Karlsson (1997) points out, amongst different ways of carrying out the Monte Carlo integration, the Gibbs sampling algorithms are less adversely affected by model size, and hence, performs no worse than other important sampling methods.'

\section{Evaluation of Forecast Accuracy:}

Table 2 reports on the forecasting performance of the univariate and bivariate versions of the VAR and BVAR, with the latter also including the Gibbs sampled models ${ }^{10}$, relative to the PIH model. We first estimated all the models including the constrained VAR with data from 1947:1 up to 1990:4 and then used the models to generate out-of sample forecasts for the change in labor income for one- to eight-quarters-ahead. Recall that, the different models are estimated with three lags for each variable(s). Since we use three lags, the initial three quarters of the sample, 1947:01 to 1947:03, are used to feed the lags. We generate dynamic forecasts, as would naturally be achieved in actual forecasting practice. The models are re-estimated each quarter

\footnotetext{
${ }^{7}$ For an illustration, see Dua and Ray (1995).

${ }^{8}$ See section 3 for further details.

${ }^{9}$ See Kadiyala and Karlsson (1997) and the references cited therein for further details.

10 The parameter estimates from the Gibbs sampled BVARs are based on 1000,000 iterations, with initial 100,000 discarded to prevent issues of initialization. Based on the 1000,000 random draws for the 7 parameters in each equation, hosts of alternative convergence tests, outlined in LeSage (1999), were carried out to ensure that the sampler converges in the limit. The convergence tests have not been reported to save space. However, all the results are available upon request from the authors.
} 
over the out-of-sample forecast horizon in order to update the estimate of the coefficients, before producing the 8-quarters-ahead forecasts. This iterative estimation and 8-steps-ahead forecast procedure was carried out for 71 quarters, with the first forecast beginning in 1991:01. This experiment produced a total of 71 one-quarter-ahead forecasts, 71-two-quarters-ahead forecasts, and so on, up to 718 -step-ahead forecasts. The RMSEs ${ }^{11}$ for the 71 , quarter 1 through quarter 8 forecasts are then calculated for the change in aggregate labor income. The model that produces the lowest average value for the RMSE is selected as the 'optimal' model for forecasting the change in labor income.

In Table 2, we compare the ratios of the RMSEs of one- to eight-quarters-ahead out-of-sampleforecasts for the period 1991:01 to 2008:03, generated by the abovementioned alternative models, relative to the PIH model. At this stage, a few words need to be said regarding the choice of the evaluation criterion for the out-of-sample forecasts generated from Bayesian models. As Zellner (1986: 494) points out the 'optimal' Bayesian forecasts will differ depending upon the loss function employed and the form of predictive probability density function". In other words, Bayesian forecasts are sensitive to the choice of the measure used to evaluate the out-of-sample forecast errors. However, Zellner (1986) points out that the use of the mean of the predictive probability density function for a series, is optimal relative to a squared error loss function and the Mean Squared Error (MSE), and hence, the RMSE is an appropriate measure to evaluate performance of forecasts, when the mean of the predictive probability density function is used. This is exactly what we do below in Table 2, when we use the average RMSEs over the one- to eight-quarter-ahead forecasting horizon. The conclusions on the forecast performance of alternative models for the change in aggregate labor income, based on the relative average oneto eight-quarters-ahead RMSEs, from Table 2 can be summarized as follows:

(i) In general, unlike Ireland $(1995)^{12}$, with the exceptions of the univariate BVAR under $w=0.3, d=0.5$, the bivariate BVAR with $w=0.1, d=0.1$ and $w=0.1, d=2.0$, and the Gibbs sample bivariate BVAR under $w=0.2, d=1.0$, the PIH model is outperformed by all other models in terms of average RMSEs for forecasting the changes in labor income; ${ }^{13}$

(ii) Amongst the univariate models, the Gibbs sampled univariate BVAR with the most tight priors i.e., $w=0.1, d=2.0$ performs the best, while, amongst the bivariate models, the Gibbs sampled BVAR, with the second most tight prior structure ( $w=$ $0.2, d=2.0$ ) stands out. However, the "optimal" Gibbs sampled univariate BVAR outperforms the optimal Gibbs sampled bivariate BVAR;

(iii) Overall, the results tends to indicate the importance of introducing a heteroscedastic error structure for forecasting changes in labor income over an out-of-sample horizon that was characterized by high degree of volatility in changes in labor income. Moreover, the fact that the most tight Gibbs sampled univarite BVAR is the stand out performer, tends to corroborate our findings in Section 3, where we

\footnotetext{
${ }^{11}$ Note that if $A_{t+n}$ denotes the actual value of a specific variable in period $t+n$ and ${ }_{t} F_{t+n}$ equals the forecast made in period $t$ for $t+n$, the RMSE statistic equals the following: $\sqrt{\left[\sum_{1}^{N}\left({ }_{t} F_{t+n}-A_{t+n}\right)^{2} / N\right]}$ where $N$ equals the number of forecasts.

12 Ireland (1995) found the PIH model to consistently outperform the classical versions of the univariate and bivariate VARs.

${ }^{13}$ Interestingly, for the one-quarter-ahead forecasts the PIH model outperforms all the univariate and bivariate versions of the VAR and BVAR based on the homoscedastic error structure, but is, in turn, out done by both the univariate and bivariate versions of the Gibbs sampled BVAR, the exception being the Gibbs sampled bivariate BVAR under $w=0.2, d=1.0$.
} 
indicated that the impact of lagged savings on labor income is virtually negligible (in magnitude, even though the impact is significant when taken together).

\section{[INSERT TABLE 2]}

\section{Conclusions}

This paper presents Hall's (1978) version of the PIH obtained from a bivariate system of labor income and savings, using quarterly data over the period of 1947:01 to 2008:03 for the US economy, and then uses the model to forecast changes in labor income over the period of 1991:01 to 2008:03. Our results indicate the overwhelming rejection of the restrictions on the data implied by the PIH. Given that Ireland (1995) argued that the permanent income hypothesis must be judged on its ability to forecast the data better than alternative models, we compared the forecast performance of the PIH model relative to the forecasts generated from the univariate and bivariate versions of both classical and Bayesian variants VAR model. Realizing that the period of 1991:01 to 2008:03 was characterized by high levels of variation in the changes in labor income we also used a Gibbs-sampled version of the BVAR model characterized by heteroscedastic disturbances to capture the non-constant variance in the data over the out-ofsample horizon. We found that, in general, the PIH model is outperformed by all other models in terms of the average RMSEs for one to eight quarters ahead forecasts for the changes in labor income, and overall it is the most tight Gibbs sampled univarite BVAR that performs the best. So to conclude, we do not find evidence for the US data to be consistent with the PIH, neither does the PIH model perform better relative to alternative atheoretical models in forecasting changes in labor income over an out-of-sample horizon that witnessed high volatility in the changes in labor income. However, it must be realized, that the results are perhaps an indication of the simplistic nature of the PIH model. As Ireland (1995) points out Hall's (1978) model makes very restrictive assumptions about the interest rate and the household's utility function. The statistical rejection of the constraints and the poor forecasting performance may thus be reflecting the failure of these additional assumptions to hold in the data, rather than a more general inapplicability of the permanent income hypothesis itself. Future research would thus aim at developing more profound models of PIH along the lines of Hansen and Singleton (1982), Campbell and Mankiw (1989), and more recently, Corradini (2005).

\section{References}

Campbell, J.Y., (1987) "Does saving anticipate declining labor income? An alternative test of the permanent income hypothesis”, Econometrica, vol. 55 (November), pp. 1249-73.

and Mankiw, N.G., (1989) Consumption, income and interest rates: reinterpreting the time series evidence, Working Paper No. 2924, National Bureau of Economic Research, Cambridge, MA.

Corradini,R. 2005. "An Empirical Analysis of Permanent Income Hypothesis Applied to Italy using State Space Models with non zero correlation between trend and cycle," Econometrics 0509009, EconWPA. 
Dejuan, J.P., Seater, J.J., and Wirjanto, T.S., (2004) "A direct test of permanent Income Hypothesis with an Application of the U.S. States", Journal of Money Credit and Banking, vol. 36, No. 6, pp. 1091-1103.

Doan, T. A., Litterman, R. B. and Sims, C. A. (1984). Forecasting and Conditional Projections Using Realistic Prior Distributions. Econometric Reviews, vol. 3, 1-100.

Dua, P. and Ray, S. C. (1995). A BVAR Model for the Connecticut Economy. Joumal of Forecasting, vol. 14, 167-180.

Fisher, I. (1907) The Rate of Interest. New York: MacMillan Company.

Friedman, M., (1957) A Theory of Consumption Function, Princeton, NJ: Princeton University Press.

Gupta, R., (2007) "Forecasting the South African economy with GIBBS sampled BVECMs", South African Journal of Economics, Volume 75(4), 631-643.

Gupta, R., (2006) "Forecasting the South African economy with VARs and VECMs", South African Journal of Economics, Volume 74(4), 611-628.

Gupta, R. and Sichei, M.M., (2006) "A BVAR Model of the South African Economy," South African Journal of Economics, vol. 74(3), pp. 391-409.

Hall, R.E., (1978) "Stochastic Implications of the Life Cycle-Permanent Income Hypothesis: Theory and Evidence", Journal of Political Economy, pp.971-987.

Hansen, L. P. and Singleton, K. J. (1982) "Generalized Instrumental Variables Estimation of Nonlilear Rational Expectations Models,” Econometrica, vol. 50, pp. 1269-86.

Ireland, P.N., (1995) "Using the Permanent Income Hypothesis for Forecasting", Federal Reserve Bank of Richmond Economic Quarterly, volume 81/1, pp. 49-63.

Kadiyala, K. R. and Karlsson, S. (1997). Numerical Methods for Estimation and Inference in Bayesian VAR- Models, Journal of Applied Econometrics, vol. 12, 99-132.

King, R.G., (1995) "Quantitative Theory and Econometrics.” Manuscript, University of Virginia.

LeSage,J.P.,(1999). Applied Econometrics Using MATLAB, www.spatial-econometrics.com.

Litterman, R. B. (1981). A Bayesian Procedure for Forecasting with Vector Autoregressions. Working Paper, Federal Reserve Bank of Minneapolis.

Litterman, R. B. (1986). Forecasting with Bayesian Vector Autoregressions - Five Years of Experience. Journal of Business and Economic Statistics, vol. 4 (1), 25-38.

Rao, B.B., (2005) “Testing Hall's permanent income hypothesis for a developing country: the case of Fiji”, Applied Economics Letters, 12, 245-248.

and Sharma, K. L., (2007) Testing the permanent hypothesis in the developing and developed countries: A comparison between Fiji and Australia. MPRA paper number 2725, 
http://mpra.ub.uni-muechen.de/2725/.

Sims, C. A. (1980). Macroeconomics and Reality. Econometrica, vol. 48, 1-48.

Spencer, D. E. (1993). Developing a Bayesian Vector Autoregression Model. International Journal of Forecasting, vol. 9, 407-421.

Theil, H. (1971). Principles of Econometrics. New York: John Wiley.

Todd, R. M. (1984). Improving Economic Forecasting with Bayesian Vector Autoregression. Quarterly Review, Federal Reserve Bank of Minneapolis, Fall, 18-29.

Zellner, A.. (1986). A Tale of Forecasting 1001 Series: The Bayesian Knight Strikes Again. International Journal of Forecasting, vol. 2, 494-494. 
Figure 1: Changes in Labor Income

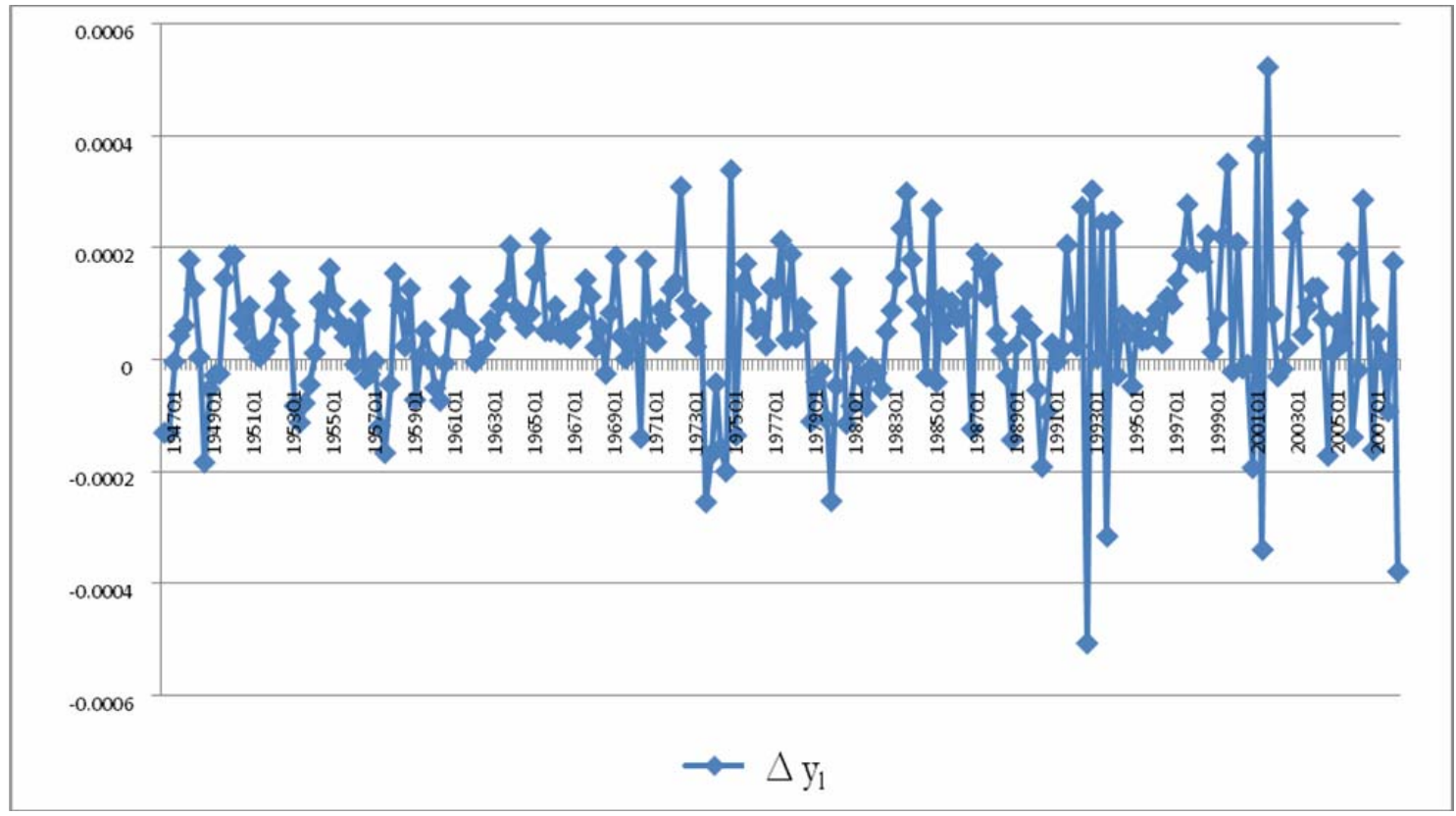

Table 1. Estimated Changes in Labor Income Equation from the PIH Model:

\begin{tabular}{|c|c|c|c|}
\hline \multicolumn{4}{|c|}{ a) Unconstrained Model } \\
\hline$\Delta \mathrm{Y}_{\mathrm{lt}}=0.000021$ & $\begin{array}{l}+0.216 \Delta \mathrm{Y}_{\mathrm{lt}-1} \\
(0.0802)\end{array}$ & $\begin{array}{l}+0.242 \Delta \mathrm{Y}_{\mathrm{lt}-2} \\
(0.0803)\end{array}$ & $\begin{array}{l}-0.0119 \Delta \mathrm{Y}_{\mathrm{lt}-3} \\
(0.0619)\end{array}$ \\
\hline & $\begin{array}{l}-0.331 \mathrm{~S}_{\mathrm{t}-1} \\
(0.0619)\end{array}$ & $\begin{array}{l}+0.204 \mathrm{~S}_{\mathrm{t}-2} \\
(0.0829)\end{array}$ & $\begin{array}{l}+0.126 \mathrm{~S}_{\mathrm{t}-3} \\
(0.0659)\end{array}$ \\
\hline \multicolumn{4}{|c|}{ b) Constrained Model } \\
\hline $\begin{array}{l}\Delta \mathrm{Y}_{\mathrm{lt}}= \\
0.000012\end{array}$ & $\begin{array}{l}+0.166 \Delta \mathrm{Y}_{\mathrm{lt}-1} \\
(0.0803)\end{array}$ & $\begin{array}{l}+0.187 \Delta \mathrm{Y}_{\mathrm{It}-2} \\
(0.0804)\end{array}$ & $\begin{array}{l}-0.0179 \Delta \mathrm{Y}_{\mathrm{lt}-3} \\
(0.0620)\end{array}$ \\
\hline & $\begin{array}{l}-0.349 \mathrm{~S}_{\mathrm{t}-1} \\
(0.0620)\end{array}$ & $\begin{array}{l}+0.260 \mathrm{~S}_{\mathrm{t}-2} \\
(0.0830)\end{array}$ & $\begin{array}{l}+0.088 \mathrm{~S}_{\mathrm{t}-3} \\
(0.0659)\end{array}$ \\
\hline
\end{tabular}

Note: Standard errors are in parentheses. 
Table 2. RMSEs Relative to PIH Model:

\begin{tabular}{|c|c|c|c|c|c|c|c|c|c|c|}
\hline & QA & 1 & 2 & 3 & 4 & 5 & 6 & 7 & 8 & Average \\
\hline & UVAR & 1.046 & 0.965 & 0.977 & 0.969 & 0.975 & 0.971 & 0.975 & 0.974 & 0.981 \\
\hline & MVAR & 1.014 & 0.979 & 0.989 & 0.984 & 0.987 & 0.983 & 0.997 & 0.992 & 0.990 \\
\hline \multirow{4}{*}{$\begin{array}{l}\mathrm{w}=0.3, \\
\mathrm{~d}=0.5\end{array}$} & UBVAR & 1.013 & 0.998 & 1.000 & 0.998 & 0.999 & 0.999 & 0.998 & 0.999 & 1.001 \\
\hline & UBVARG & 0.005 & 0.014 & 0.003 & 0.006 & 0.016 & 0.193 & 0.420 & 0.053 & 0.089 \\
\hline & MBVAR & 1.025 & 0.974 & 0.986 & 0.980 & 0.986 & 0.982 & 0.997 & 0.992 & 0.990 \\
\hline & MBVARG & 0.815 & 0.568 & 0.764 & 0.554 & 0.548 & 1.100 & 1.088 & 2.163 & 0.765 \\
\hline \multirow{4}{*}{$\begin{array}{l}\mathrm{w}=0.2, \\
\mathrm{~d}=1.0\end{array}$} & UBVAR & 1.08 & 0.96 & 0.98 & 0.97 & 0.97 & 0.97 & 0.97 & 0.97 & 0.98 \\
\hline & UBVARG & 0.03 & 0.11 & 0.08 & 0.09 & 0.18 & 0.18 & 0.41 & 0.05 & 0.02 \\
\hline & MBVAR & 1.05 & 0.97 & 0.99 & 0.98 & 0.99 & 0.98 & 1.00 & 0.99 & 0.99 \\
\hline & MBVARG & 129.50 & 0.57 & 2.22 & 5.54 & 18.63 & 61.59 & 200.66 & 659.30 & 121.59 \\
\hline \multirow{4}{*}{$\begin{array}{l}w=0.1, \\
d=1.0\end{array}$} & UBVAR & 1.165 & 0.956 & 0.987 & 0.963 & 0.978 & 0.970 & 0.975 & 0.974 & 0.995 \\
\hline & UBVARG & 0.136 & 0.222 & 0.139 & 0.249 & 0.088 & 0.401 & 0.321 & 0.671 & 0.028 \\
\hline & MBVAR & 1.146 & 0.963 & 1.000 & 0.974 & 0.993 & 0.983 & 1.001 & 0.993 & 1.006 \\
\hline & MBVARG & 0.592 & 0.568 & 0.556 & 0.554 & 0.548 & 1.100 & 2.719 & 5.949 & 1.599 \\
\hline \multirow{4}{*}{$\begin{array}{l}\mathrm{w}=0.2, \\
\mathrm{~d}=2.0\end{array}$} & UBVAR & 1.078 & 0.962 & 0.978 & 0.967 & 0.975 & 0.970 & 0.974 & 0.973 & 0.984 \\
\hline & UBVARG & 0.124 & 0.256 & 0.439 & 0.897 & 1.687 & 3.767 & 7.553 & 15.609 & 3.876 \\
\hline & MBVAR & 1.046 & 0.971 & 0.987 & 0.978 & 0.987 & 0.983 & 0.998 & 0.992 & 0.992 \\
\hline & MBVARG & 0.592 & 0.568 & 0.556 & 0.554 & 1.096 & 0.550 & 1.088 & 0.608 & 0.626 \\
\hline \multirow{4}{*}{$\begin{array}{l}\mathrm{w}=0.1, \\
\mathrm{~d}=2.0\end{array}$} & UBVAR & 1.165 & 0.956 & 0.987 & 0.963 & 0.978 & 0.970 & 0.975 & 0.974 & 0.995 \\
\hline & UBVARG & 0.002 & 0.074 & 0.209 & 0.180 & 0.065 & 0.103 & 0.110 & 0.203 & 0.012 \\
\hline & MBVAR & 1.146 & 0.963 & 1.000 & 0.974 & 0.993 & 0.983 & 1.001 & 0.993 & 1.006 \\
\hline & MBVARG & 0.814 & 0.568 & 0.556 & 0.762 & 1.096 & 0.550 & 1.088 & 2.163 & 0.765 \\
\hline
\end{tabular}

Notes: QA: QUARTERS AHEAD; UVAR: UNIVARIATE VAR; MVAR: BIVARIATE VAR; UBVAR: UNIVARIATE BVAR; UBVARG: GIBBS SAMPLED UBVAR; MBVAR: BIVARIATE BVAR; MVARG: GIBBS SAMPLED MBVAR. 